\title{
Empresa HD, aluno monitor: a Microsoft e a construção da crença nas tecnologias
}

Michelle Prazeres'

\section{Resumo}

Existe um consenso de que as tecnologias digitais podem incidir na melhoria da qualidade da educação. Articulado por múltiplos campos sociais interessados na relação entre educação e tecnologias, um universo simbólico de valores (em geral, positivos) relacionados aos aparatos digitais se converte em repertório que consagra esse consenso e o transforma em uma espécie de mito, uma crença. Esse mito circula por diversos espaços sociais, formando uma ambiência favorável às tecnologias, que envolve o campo educacional (em inter-relação com outros campos sociais) e pressiona a escola pela modernização a partir da adesão às tecnologias. Este artigo tem como objetivo promover uma reflexão acerca da contribuição do campo empresarial para a conformação dessa ambiência favorável à modernização, a partir da análise do repertório produzido e difundido pela multinacional Microsoft acerca do uso das tecnologias na educação. Esse repertório está registrado em relatórios corporativos que foram analisados para entender de que modo representam: (1) o impacto das tecnologias na educação; o modo como a educação adere às (2) tendências tecnológicas; e (3) os efeitos e potenciais das linguagens tecnológicas em espaços educativos. Entende-se que a empresa pretende ter uma ação totalizante relacionada à educação, prescrevendo o uso das tecnologias em materiais institucionais, incidindo na mídia e na universidade e atuando em parceria com governos para a adoção de seus equipamentos, produtos e programas. Com base nos relatórios institucionais, investiga-se o corpo simbólico produzido pela Microsoft, que integra e reforça uma rede em prol das tecnologias, composta também por outros campos sociais interessados na modernização da educação, a exemplo do poder público, da mídia e da universidade.

\section{Palavras-chave}

Educação - Tecnologias - Socialização - Cibercultura - Microsoft
I- Universidade de São Paulo, São Paulo, SP, Brasil.

Contato: michelleprazeres@gmail.com 


\title{
HD company, monitor student: Microsoft and the construction of belief in technologies
}

Michelle Prazeres ${ }^{\prime}$

\begin{abstract}
There is a consensus that digital technologies are able to positively change the quality of education. Through the articulation of multiple social fields interested in the relationship between education and technologies, a symbolic universe of (usually positive) values related to digital devices is converted into a repertoire which enshrines this consensus and turns it into a kind of myth, a belief. This myth is spread over several social spaces and it shapes a favorable environment for technologies, which involves the field of education (in an interrelation with other social fields) and puts pressure on schools for modernization through the adoption of technologies. This article aims to reflect on the contribution of the corporate field for the shaping of this favorable environment for modernization, based on the analysis of the repertoire created and disseminated by Microsoft regarding the use of technologies in education. This repertoire is registered in corporate reports, which have been analyzed in order to understand how they represent (1) the impact of technologies on education; the way education embraces (2) technological trends; and (3) the effects and potential of technological languages in education spaces. It is understood that the company intends to have an allencompassing action towards education, prescribing the use of technologies in institutional material, focusing on the media and universities, and working in partnership with the government for the adoption of their equipment, products and software. Based on institutional reports, we examine the symbolic material produced by Microsoft, with comprises and strengthens a network in favor of technologies, also formed by other social fields interested in modernizing education, such as the government, the media and universities.
\end{abstract}

\section{Keywords}

Education - Technologies - Socialization - Cyberculture - Microsoft

I- Universidade de São Paulo, São Paulo, SP, Brasil.

Contact: michelleprazeres@gmail.com 


\section{Introdução}

Existe um consenso de que as tecnologias digitais podem incidir na melhoria da qualidade da educação. Articulado por múltiplos campos sociais interessados na relação entre educação e tecnologias, um universo simbólico de valores relacionados aos aparatos digitais se converte em repertório que consagra esse consenso e o transforma em uma espécie de mito, uma crença. Este mito circula por diversos espaços sociais, formando uma ambiência favorável às tecnologias, que envolve o campo educacional e pressiona a escola pela modernização a partir da adesão às tecnologias nos processos educativos. Tal pressão se dá sob a forma de projetos específicos e também de políticas públicas, que respondem ao coro pela modernização, levando equipamentos, programas e um modelo mental tecnológico para alunos, professores e escolas. A crença nas tecnologias está instalada no coração da sociedade contemporânea de tal forma que (1) pode ser entendida como uma cultura que atravessa as demais - a cibercultura; e (2) é difícil e rara a contestação de suas engrenagens, valores e esquemas estruturantes.

Partindo do entendimento de que existem diversos campos interessados na relação entre educação e tecnologias e que esse interesse compartilhado contribui para a dinâmica de construção de um repertório comum que tende a valorizar o uso das tecnologias em processos educativos, este artigo analisa como a empresa de tecnologia Microsoft constrói, publica e dissemina um discurso a respeito da necessidade e positividade das tecnologias na educação.

Cabe informar que este estudo está relacionado a uma investigação mais ampla, que busca entender a complexidade de um fenômeno que se nomeou de moderna socialização escolar, que diz respeito à introdução contínua das tecnologias nas escolas, a partir da construção silenciosa e velada da crença em suas potencialidades e realizações. Integra, assim, um mapeamento amplo de representações a respeito da moderna socialização escolar, a partir da análise de documentos representativos dos repertórios de campos sociais interessados na modernização da educação via tecnologias, como poder público, mídia, empresas e universidade ${ }^{1}$.

Tal mapeamento foi construído a partir da análise minuciosa de documentos relacionados a esses campos e sua atuação no estado de São Paulo. A seleção da amostra e do procedimento de análise foi um trabalho artesanal. Sabia-se que não se desejava realizar uma análise de discurso clássica, pois se pretendia mapear elementos discursivos, representações subjetivas e valores neles contidos. 0 método escolhido foi o que se chamou de olhar relacional: ou seja, um exercício teórico-metodológico de promover um encontro entre os documentos, as hipóteses e objetivos da pesquisa, em permanente diálogo.

Em relação aos relatórios da Microsoft, o primeiro passo consistiu na sua leitura. Nessa etapa, buscou-se listar ideias e categorias-chave presentes nos documentos como, por exemplo, avaliação, gestão, transformação/impacto nas vidas dos sujeitos, aprendizagens, práticas, acesso etc. Chegou-se assim a um primeiro mapa das representações acerca das tecnologias em contextos educacionais.

Em uma segunda leitura para validar tais ideias, deu-se a tomada de consciência de que elas poderiam ser agrupadas em três categorias básicas - impacto, tendências e linguagem ${ }^{2}$. Definidas tais categorias, a atenção voltou-se novamente aos documentos para a execução do processo final de classificação.

Ao construir e optar por esse método, o esforço seguinte foi o de buscar nos documentos os aspectos centrais, evidentes ou preponderantes em cada texto para classificá-los sem deixar de registrar quando um deles representava mais de uma ideia básica ou categoria. Desse modo, acredita-se ter detectado as sinergias e

1- Para maiores informações, confira o trabalho de Prazeres (2013).

2- A categoria 1 se refere à tecnologia como elemento transformador da realidade da educação e das pessoas; a categoria 2 relaciona 0 uso da tecnologia ao avanço, ao desenvolvimento e ao futuro; e a categoria 3 trata da tecnologia enquanto expressão de época ou geração. 
divergências no tratamento de cada eixo institucional de cada um dos temas em questão.

A escolha pelos documentos de poder público, mídia, empresas e universidade não foi fortuita. Ela obedeceu a uma evidência empírica. Em primeiro lugar, todos podem ser considerados como campos de atuação: espaços estruturados em que agentes e instituições travam lutas a partir de suas posições e das relações dinâmicas que estabelecem entre si (BOURDIEU, 2004a, 2004b, 2010).

Em segundo lugar, cada campo é composto por agentes, instituições, valores e regras. Os agentes e as instituições desses campos se organizam em redes que notadamente produzem e difundem valores, bem como se posicionam quando o assunto é a modernização da educação.

0 complexo emaranhado de agentes e instituições envolvidos no processo de valorização, adoção e uso de mídias e tecnologias nas escolas inclui alunos, professores, gestores, pais, consultores, técnicos, políticos, entre outros; escolas públicas e privadas, diretorias regionais, organizações da sociedade civil, empresas, prefeituras, governos estaduais e o federal. Juntos, e se relacionando, esses agentes e instituições conformam uma rede que parece extrapolar os muros da escola e as fronteiras do campo educacional. Ainda que a moderna socialização escolar se traduza, na prática, em ações via tecnologias - na e para a escola -, entende-se que é a complexidade dessa trama que gesta o multidimensional processo de construção de um consenso que a consagra e a promove. Portanto, essa rede carece de estudo e desvelamento.

Como questão de fundo, busca-se compreender a relação entre o campo educacional e as tecnologias, entendidas simultaneamente como "instituição, linguagem, estética, formato industrial e epistemologia que contém uma lógica de produção, distribuição e consumo" (OROZCO GÓMEZ, 2001). Tal entendimento compreende a cibercultura enquanto ambiência ampla, que ocupa posição central em nossa sociedade. Não se trata da cultura das mídias apenas em ato de conexão ou simplesmente da cultura inerente à internet ou às conexões em rede, mas da cultura de um tempo, do espírito de uma época (TRIVINHO, 2007), da ambiência da contemporaneidade, do sensorium (BENJAMIN, 1996); ou ainda: de um entorno (MARTÍNBARBER0, 2007), tão presente para os indivíduos na contemporaneidade quanto o natural e o social. Trata-se de uma cultura que atravessa a vida do indivíduo hoje, capaz de perpassar a existência humana e as demais culturas e matrizes culturais de modo determinante.

Nesse sentido, o conceito de cibercultura é entendido tanto como o arranjo material, simbólico e imaginário contemporâneo quanto como os processos sociais internos (estruturais e conjunturais) que lhe dão sustentação (TRIVINHO, 2007, p. 59). Ou seja, está presente nos indivíduos, nas instituições e no modus operandi contemporâneos; e, ainda que encontre suporte em suas estruturas materiais, extrapola-as, estabelecendo-se como presença no âmbito da psique, mesmo na ausência de suas ferramentas e representantes institucionais. Em sua tendência totalizante, essa cultura possui modos próprios de funcionamento $\mathrm{e}$ valores, entre eles, os da inovação tecnológica (CAZELOTO, 2005), da inclusão (digital), da velocidade, da eficiência, da interatividade, da conectividade, da mobilidade, da visibilidade, da flexibilidade, do desejo por mudança, do progresso, da transformação e do lúdico.

Vale acrescentar que tais valores estão constantemente associados a uma ideia de progresso, à qual estamos suscetíveis por se tratar, inevitavelmente, de algo positivo. Por sua vez, esse progresso remete ao novo, como se esse novo se constituísse apenas de coisas boas. Portanto, a modernização só encerraria bons aspectos, o que explica o fato de sua noção estar constantemente acompanhada de sentidos de desenvolvimento e de caminhos que conduzem ao ápice.

Assim, a cibercultura está associada a uma lógica utópica: a uma - assim chamada - 
revolução que o mundo tecnológico poderia trazer para as vidas cotidianas dos indivíduos. E, claro, igualmente, para os ambientes educativos. Pode-se afirmar que os valores relacionados a essa cultura constituem um "novo modo de ser" que mitifica a tecnologia, transformando-a em uma crença ideológica (SETTON, 2011). Parte-se do pressuposto de que essa crença marca a condição contemporânea do campo da educação, que - obrigado a seguir e acompanhar o ritmo de um novo tempo - vê-se constrangido a aderir a demandas de outros campos para não perder o bonde da história.

\section{Mapeando a ação da Microsoft na educação}

Compreendendo a cibercultura enquanto ambiência e considerando os campos interessados na moderna socialização escolar, destaca-se neste artigo a ação do campo empresarial, representado pela multinacional Microsoft. Busca-se compreender como a empresa representa a moderna socialização escolar, pois veicula valores empresariais, contribuindo (1) para a conformação da orquestração de sentidos favorável à modernização; e (2) para a adesão a programas que transmutam essa crença em políticas educacionais de uso de tecnologias. A análise concentra-se no Programa Aluno Monitor, ação da empresa que se considera um dos expoentes desse processo.

Cabe ressaltar que a escolha da empresa Microsoft como expoente do campo empresarial não se deu ao acaso. Além de ser uma das maiores empresas do mercado tecnológico do mundo, a Microsoft desenvolve uma ação que pretende ser totalizante no que diz respeito à moderna socialização escolar, atuando em múltiplas frentes, que cumprem o papel de reforçar o ideário da empresa em diferentes campos sociais. Se o processo de socialização dos indivíduos se dá a partir da "articulação entre matrizes de sentido responsáveis pela formação de sujeitos sociais singulares" (SETTON, 2009), uma ideia ou valor presente em múltiplas instâncias ou espaços de socialização pode ter um maior potencial de adesão por parte dos indivíduos.

Para construir o mapa de representações da Microsoft acerca da moderna socialização escolar, foram analisados os Relatórios de cidadania corporativa da empresa, publicados entre os anos de 2004 e $2011^{3}$. Os documentos foram analisados com base nas três categorias:

1. impacto; 2 . tendências; e 3 . linguagem.

0 título deste artigo faz uma alusão a dois componentes de um computador. É uma licença poética que tem como intenção sensibilizar o leitor para uma inquietação: o Hard disk (HD) ou disco rígido é a parte do computador responsável pelo armazenamento de dados, a sua memória; já o monitor é a tela do computador, em que é possível visualizar a interface da máquina, responsável por conduzir as informações a seus usuários. 0 jogo de palavras contém uma questão: seriam os alunos do Programa Aluno Monitor da Microsoft condutores de informação? Seria a empresa a mantenedora de um repertório lógico, criadora, produtora e divulgadora do conhecimento nas atividades previstas no programa? Esta é uma das provocações que move este artigo.

Os relatórios são documentos institucionais que apresentam números e casos que a empresa considera de sucesso na utilização dos seus produtos e soluções em escolas, tanto no âmbito das práticas pedagógicas quanto no âmbito da gestão. Voltados para funcionários, apoiadores, financiadores e para o público em geral, e organizados como forma de prestação de contas à sociedade da ação de seus braços sociais, os relatórios obedecem a uma lógica de construção: (1) seus títulos representam leituras sintéticas da empresa sobre a realidade, a conjuntura nacional e o contexto do Brasil no período em que o documento foi publicado; e (2) seus conteúdos são elaborados

3 - 0 período foi escolhido porque, em 2004, o Programa Aluno Monitor foi criado e em 2011 foi analisado o último relatório da empresa, posto que se fez necessário o fechamento da amostra de pesquisa. No entanto, 0 projeto continua em vigência. 
explorando resultados numéricos, mas também buscando personagens e histórias que possam conferir concretude e realidade àqueles números e cifras. Dessa forma, os documentos se constituem em preciosas fontes acerca do repertório da empresa a respeito da moderna socialização escolar.

Tabela 1 - Títulos dos relatórios anuais da Microsoft.

\begin{tabular}{|c|c|c|}
\hline Ano & Título do relatório & $\begin{array}{l}\text { Título da apresentação do } \\
\text { presidente }\end{array}$ \\
\hline 2004 & $\begin{array}{c}\text { Compromisso com o } \\
\text { Brasil }\end{array}$ & Inclusão social: uma meta possível \\
\hline 2005 & $\begin{array}{l}\text { Seu potencial, nossa } \\
\text { inspiração }\end{array}$ & $\begin{array}{l}\text { Potenciais, inspirações e } \\
\text { realizações }\end{array}$ \\
\hline 2006 & $\begin{array}{l}\text { Seu potencial, nossa } \\
\text { inspiração }\end{array}$ & Microsoft Brasil: cidadania global \\
\hline 2007 & Potencial ilimitado & Tecnologia para a inovação \\
\hline 2008 & Microsoft Brasil 20 anos & Compromisso com a inovação \\
\hline 2009 & 20 & Somar para multiplicar \\
\hline 2010 & $\begin{array}{l}\text { A gente inova, você } \\
\text { transforma }\end{array}$ & $\begin{array}{c}\text { Protagonistas de um futuro sem } \\
\text { pobreza }\end{array}$ \\
\hline 2011 & $\begin{array}{l}\text { Todos os dias perto de } \\
\text { você }\end{array}$ & $\begin{array}{l}\text { Mais do que nunca, comprometidos } \\
\text { com a América Latina }\end{array}$ \\
\hline
\end{tabular}

Fonte: Elaboração da autora.

A tabela 1 apresenta os títulos dos relatórios e das mensagens dos presidentes contidas em cada anuário. Supõe-se que o título geral (que consta na capa) apresenta valores mais relacionados à missão da empresa e que a mensagem do presidente carrega, por sua vez, aspectos mais relacionados à questão social e de responsabilidade corporativa e cidadania.

Nos títulos dos documentos, as mensagens parecem ser mais corporativas ou relacionadas à trajetória da empresa, ao mercado ou à questão econômica. É possível visualizar valores como: o compromisso da empresa com o Brasil; o potencial do país como motor para as ações da empresa (a palavra potencial é mencionada em três títulos); mensagens mais institucionais, como as duas que celebram os vinte anos da empresa; bem como valores relacionados ao universo simbólico cibercultural, como inovação, transformação e conectividade (proximidade).
Já nos títulos das mensagens dos presidentes, ficam evidentes questões de cunho mais social, como inclusão, cidadania, protagonismo e futuro sem pobreza. Parece que o papel destas mensagens é justamente o de conectar a mensagem empresarial à de ação social. Os títulos parecem buscar equilibrar os valores de cidadania e ações filantrópicas aos valores econômicos e mercadológicos, usando também expressões como potencial, realizações, inovação etc. Um elemento relevante nos títulos das mensagens dos presidentes é o caráter internacional das ações da empresa. Em expressões como global, isso fica evidente, e também quando se fala em compromisso com a América Latina.

\section{Uma ação totalizante}

Os relatórios corporativos da Microsoft parecem indicar que a ação da empresa em matéria de educação se pretende totalizante, na medida em que abrange várias dimensões, caracterizando uma ação socializadora complexa e inexorável.

A análise do material mostrou que a Microsoft é uma instituição do campo empresarial das comunicações e tecnologias que (1) investe em projetos educacionais com uso de seus recursos tecnológicos por meio de um braço social; (2) gera projetos em parceria com poderes públicos, incidindo em políticas públicas educacionais; (3) tem seu repertório divulgado pelo campo das mídias; e (4) lança mão de outras estratégias de visibilidade, como assessoria de imprensa e premiações. Por fım, a Microsoft (5) incide também no campo acadêmico, sendo objeto de estudo direto de teses, dissertações e artigos ${ }^{4}$. Neste campo, a empresa também desenvolve uma ação direta de fomento a pesquisas, por meio de seu Instituto

4- Em uma busca simples nos sites Domínio Público (<http://www. dominiopublico.gov.br>) e Banco de Teses da Capes (<http://www.capes. gov.br/servicos/banco-de-teses>), foram encontrados 571 estudos que continham, em suas palavras-chave, títulos ou resumos, o termo Microsoft. 
Microsoft Research - FAPESP de Pesquisas em Tecnologia da Informação $0^{5}$.

Além de estar presente de diversas formas em múltiplos campos, a Microsoft é um dos maiores expoentes da cultura tecnológica no mundo. Como se sabe, a formação para a cibercultura tem múltiplos aspectos e não se dá apenas via aparatos materiais, mas também diz respeito a um corpo simbólico e lógico. A incursão da empresa no setor educacional pode ser, portanto, uma de suas estratégias de ampliação de mercado.

No Brasil, a atuação da empresa na área da educação é vasta e se dá por meio de projetos e oferta de soluções destinadas à modernização da educação $0^{6}$. A ação nacional se divide em três âmbitos: educação superior, educação básica e produtos e soluções (de gestão). Na visão de inovação da empresa, a mudança na educação ${ }^{7}$ seria conquistada através de: (1) formação de educadores; (2) acesso à tecnologia para educadores e alunos; e (3) acesso à tecnologia para a instituição. A ação prática relacionada a esses pilares se dá de forma cruzada com a iniciativa Parceiros da Aprendizagem, cuja missão institucional seria "auxiliar alunos e educadores a alcançarem seu potencial pleno”.

Um texto de apresentação no website da empresa demonstra o que a iniciativa representa para a Microsoft: a possibilidade de incidir na educação e promover uma verdadeira revolução:

Parceiros na Aprendizagem é uma iniciativa mundial da Microsoft que visa disponibilizar tecnologias e apoio pedagógico para o desenvolvimento do potencial pleno de gestores, educadores, estudantes e comunidade escolar. É um compromisso para melhorar

5- A iniciativa apoia "projetos de pesquisa em Tecnologias de Informação e Comunicações propostos por pesquisadores associados a universidades e institutos de pesquisa no Estado de São Paulo". Para mais, veja-se: $<$ http://www.fapesp.br/2820>.

6- Informações do portal: <http://www.microsoft.com/brasil/educacao/ default.mspx>.

7- Baseado em apresentação da empresa na Semana de Educação 2011. Disponível em: <http://download.microsoft.com/download/B/F/F/ BFF86CC6-8C6A-4C9C-B3FE-5A6B251D78FA/Semana_de_EducacaoVisao_de_Inovacao.pdf>. a qualidade da educação e ampliar a inclusão digital e social por meio dos recursos da tecnologia. [...] Os programas possibilitam desde licenças mais acessíveis para uso dos softwares Microsoft em instituições de ensino, até o desenvolvimento de projetos inovadores que necessitam de apoio pedagógico e tecnológico especializado para sua implementação, com o intuito de alcançar o maior número de professores e alunos. Várias escolas de vários países estão incorporando estas novas possibilidades, já demonstrando resultados surpreendentes no processo de ensino e aprendizagem, movendo as esperanças de melhoria sociocultural para patamares nunca antes imaginados. (MICROSOFT, 2012).

0 alcance do que a empresa qualifica como potencial pleno por parte de educadores, estudantes e escolas ou ambientes educativos estaria relacionado ao "uso das tecnologias para apoio ao desenvolvimento de competências”. Para a multinacional, essa dimensão está diretamente vinculada à promoção de comunidades de aprendizagem e à expansão de práticas inovadoras.

Nos materiais de promoção e divulgação dos projetos, essas iniciativas e práticas pedagógicas estão relacionadas a diversos valores da educação moderna. Os valores mais marcantes e reiteradamente publicados pela empresa são: inovação e mudança; e qualidade educacional e inclusão social. A primeira dupla de valores estaria mais diretamente relacionada ao negócio da Microsoft: a tecnologia; enquanto a segunda dupla estaria mais vinculada ao principal setor de atuação do braço social da empresa: a educação. Novamente aqui, é possível perceber a estratégia da empresa, visualizada nos títulos e noções mais presentes nos relatórios: seus documentos constroem constantemente os laços entre uma ação mercadológica e o que seria a sua ação social.

Parte integrante dessa ação ampla, o Programa Aluno Monitor articula as ações 
empresarial e social da empresa e tem como objetivo formar "alunos para multiplicação das competências pedagógicas para o uso das tecnologias”. Essa informação pode auxiliar a compreender como se dão as articulações de sentidos e valores entre campos para a construção de políticas modernizantes da educação. A iniciativa é desenvolvida em parceria com o poder público do estado de São Paulo (e outros 18 estados) e voltada para estudantes de ensino fundamental como o objetivo de:

[...] promover a formação em conceitos básicos de tecnologia, o gerenciamento do laboratório de informática das escolas e a multiplicação de conhecimentos para educadores e alunos. (MICROSOFT, s.d.)

Em termos práticos, o Programa Aluno Monitor é composto de um curso on-line de 140 horas de estudo, aplicado por instituições ou secretarias de educação. É composto por fases, que abrangem conhecimentos necessários para lidar tanto com as características físicas quanto com lógicas do computador: (1) primeiros passos; (2) conhecendo o computador; (3) sistemas operacionais; (4) redes; (5) manutenção de microcomputadores; e (6) programas de produtividade (orienta no uso dos programas mais populares da Microsoft, tais como Word, Excel e Power Point).

Dentro das estratégias educacionais da Microsoft no Brasil, o aluno monitor integra a iniciativa Parceiros da Aprendizagem, desenvolvida em conjunto com empresas e instituições que a Microsoft chama de Parceiros Técnicos de Cidadania, que seriam: a Universidade Estadual de Londrina (UEL), o Instituto Paramitas, as consultorias Digicad Informática e Educommatica - Educação, Comunicação e Informática, a Fundação Bradesco, o Instituto Crescer para a Cidadania, o MSTech, o Planeta Educação e a Pontifícia Universidade Católica de São Paulo.

Em seu site, a empresa divulga resultados do programa, como estratégia de reforço de sua legitimidade e de visibilidade aos projetos educacionais. No espaço virtual, afirma que está:

[...] "transformando a educação em cifras" e publica que a iniciativa Parceiros da Aprendizagem pode ser representada pelos seguintes números: 2 milhões de professores capacitados; 70 milhões de estudantes beneficiados; 252 mil professores registrados na Rede de Professores Inovadores; e US\$ 30 milhões investidos. (MICROSOFT, s/d).

No Relatório de impactos na sociedade ,publicado pela empresa no ano de 2010, e disponível em seu site (MICROSOFT, 2010), a empresa cita dados do estudo Auxílio para a recuperação: o impacto econômico de TI, software e do ecossistema da Microsoft na economia, realizado pela consultoria International Data Corporation (IDC) em outubro/2009. Os números dão conta de que a Microsoft Brasil lidera uma cadeia de valor (que chama de ecossistema de parceiros), formada por 18 mil empresas de Tecnologia da Informação e Comunicação. Esse universo gerou mais de R\$ 31 bilhões em receita em 2009; cada real gerado pela Microsoft Brasil rende outros 12,17 reais para o ecossistema de parceiros; esse ecossistema emprega 230 mil pessoas e outros 418 mil profissionais trabalham com softwares ou produtos com tecnologia Microsoft.

Note-se que, até o ano de 2010, os relatórios eram chamamos de Relatórios de cidadania corporativa ou, ainda, de Relatórios de responsabilidade social. No ano de 2010, a nomenclatura mudou e a empresa passou a utilizar o termo Impacto no título dos documentos. A nosso ver, esta alteração não se dá de forma neutra. Existe, de fato, uma busca por promover transformações grandiosas, rupturas, uma verdadeira revolução na educação a partir das tecnologias, princípio conforme a cibercultura é entendida enquanto cultura de época.

A noção de ecossistema utilizada pela empresa no documento de 2010 é outro elemento de repertório que está em sinergia com 
a cibercultura e com o processo da moderna socialização escolar, entendido como a construção de uma ambiência favorável à modernização da educação via tecnologias. 0 termo pode ajudar a compreender a ação em rede para a construção do repertório compartilhado acerca da inovação tecnológica que buscamos mapear neste estudo. Trata-se da construção de um entorno positivo, que reforça também o argumento de que a ação da Microsoft no setor educacional pretende ser multidimensional e totalizante.

Impacto: a Microsoft transformando a vida dos jovens

Os relatórios representam a voz e os valores institucionais da Microsoft e divulgam a posição fundamental da empresa. Além de expressar tais valores a partir de mensagens institucionais próprias, a empresa convida alguns agentes e instituições externas para oferecer depoimentos relacionados à sua ação em textos cujos formatos se aproximam do jornalístico. Tais agentes são personagens, ao contar histórias de vida; ou especialistas, que oferecem suas palavras com o intuito de legitimar a posição da empresa acerca de um determinado aspecto de sua ação.

Considerando a voz da empresa e também as vozes convidadas a falar a respeito da sua ação, o ordenamento das informações mostra que o impacto das tecnologias na vida das pessoas e em processos sociais é o principal tema abordado pelos relatórios.

A empresa tem interesse na legitimidade de suas iniciativas, com ênfase na transformação da vida das pessoas envolvidas no processo de modernização, sejam elas educadores, alunos ou gestores. Essa visão pode estar relacionada a certo tipo de socialização escolar na contemporaneidade. Nesse caso, uma socialização marcada pelos valores da cibercultura. Em alguns trechos dos documentos, a Microsoft explicita declaradamente o desejo de marcar essa socialização por meio da inclusão digital:
O Programa Aluno Monitor é realizado em parceria com prefeituras e governos estaduais. Por meio de um curso de 140 horas, alunos dos ensinos fundamental e médio recebem noções básicas de Tecnologia da Informação que podem contribuir para a inserção dos estudantes no mercado de trabalho. Cerca de 31 mil participaram do programa em 2009. A ação promove a inclusão digital e a socialização dos jovens. (MICROSOFT BRASIL, 2009, p. 22).

Ainda que o termo seja usado pela própria empresa como sinônimo de formação social ou formação educacional dos jovens, cabe uma incursão pelo modo como se entende socialização neste estudo. Trata-se de um processo contínuo de transmissão e legitimação cultural (BERGER; LUCKMANN, 1983). Aqui, além dessa acepção mais ampla, a noção de cultura adquire o significado trabalhado por Bourdieu (2008; 2009), de práticas culturais que tecem relações sociais e mantêm formas simbólicas em contextos ao mesmo tempo estruturados, estruturantes e dinâmicos.

Portanto, socializar-se seria a capacidade sistemática ou difusa de estabelecer uma visão de mundo por meio de processos formais ou informais, intencionais ou dissimulados de aprendizado. Ou seja, um processo que, ainda que pareça desinteressado, não o é . Nesse sentido, não se trata de um processo harmonioso, mas de um constante jogo de forças, tensões e resistências. Numa palavra: de negociação entre indivíduos e matrizes de socialização, sendo as matrizes os corpos materiais e simbólicos que produzem, transmitem e legitimam os valores e as visões de mundo que circulam nos processos socializadores. Vale ressaltar que a negociação promovida pelo indivíduo em relação aos conteúdos e formatos das mensagens socializadoras não é necessariamente uma postura crítica em relação a estes. 0 produto da negociação é, antes de tudo, um entendimento daquela mensagem promovido pelo indivíduo a partir do seu estoque de conhecimento (MATTELART, 2000), 
podendo originar uma relação de harmonia ou tensão com aquela mensagem. Ou seja, ao negociar, o indivíduo confere um sentido à mensagem, a partir do que Martín-Barbero (2007) chama de mediações.

Além de ser um processo de negociação de sentidos, toda socialização é marcada pela relação entre as diversas matrizes com as quais o indivíduo estabelece relações. Estas matrizes estão em inter-relação constante, sendo que o produto dessa relação permanente constitui uma trama de sentidos, uma configuração (SETTON, 2002). Entender a socialização como um processo de negociação permite que se rompa com a ideia de que as instituições socializadoras e seus agentes sejam antagônicos. Salienta-se assim a relação de interdependência das instâncias e dos agentes da socialização. Deste modo, concorda-se com Setton (2005): o processo de socialização contemporâneo possui uma particularidade a partir da emergência de novos modelos de socialização. A contemporaneidade diz respeito a uma configuração social e cultural altamente complexa, e um único olhar - para apenas uma ou outra matriz de socialização - não é capaz de oferecer uma compreensão adequada do processo em sua integridade.

A socialização e os processos de incorporação estão marcados, na contemporaneidade, pela inter-relação entre as diversas matrizes de cultura, entre elas, a escola, as empresas e a mídia. Como foi possível checar no relatório da Microsoft, a empresa se coloca como instituição socializadora de jovens. E, de fato, o é. Em diversos trechos de diferentes documentos, é possível encontrar histórias de vida que sofreram rupturas após o contato com os aparatos e o conhecimento oferecidos pela empresa aos alunos através do Projeto Aluno Monitor:

Desde que participou do Aluno Monitor, um dos projetos do Parceiros na Aprendizagem, o estudante José Eduardo da Silva Alves mudou sua rotina na escola estadual que frequenta, em Guarabira, interior da
Paraíba. Eduardo, que tem 19 anos e cursa o $2^{\circ}$ ano do ensino médio, ia à escola no período da tarde só para assistir às aulas. No resto do dia, jogava bola, dormia ou conversava com os amigos. Depois de tornar-se monitor, ele passa as manhãs e as noites no laboratório de informática da escola, ajudando colegas e professores. Vai à escola até nos finais de semana, para dar aulas de computação para pessoas da comunidade. 0 comportamento em sala de aula também é diferente. (MICROSOFT BRASIL, 2004. p. 16).

Nesse trecho do relatório de 2004, o aluno, após o contato com as tecnologias, adquiriu responsabilidade e "se tornou mais assíduo e interessado”. Em outro relatório, o registro se dá do ponto de vista da escolha profissional:

Em 2009, o Programa Aluno Monitor deu a 31 mil jovens a oportunidade de ser monitor em escolas e telecentros. Jéssica Kathleen Chagas Barros fez parte desse time. Exaluna da Escola Estadual César Donato Calabrez, em Guaianases, São Paulo, ela conta que a monitoria foi decisiva para a escolha de sua profissão. "Nos cursos que fiz para atuar na sala de informática da escola, aprendi a mexer com edição de imagens e gostei", explica. "Então me decidi pelo curso de publicidade e propaganda." Hoje, ela cursa o primeiro ano dessa carreira nas Faculdades Metropolitanas Unidas. (MICROSOFT BRASIL, 2009. p. 23).

Ou seja, pode-se considerar que disposições foram apresentadas a esses alunos pela empresa, enquanto instância socializadora. Em negociação com esses conteúdos, estabeleceram-se configurações de sentido nesses indivíduos, cujos dispositivos foram acionados na tomada de decisão à escola e em relação à escolha profissional.

Percebe-se que o convite a depoentes para oferecerem seus pontos de vista nos 
relatórios é uma estratégia de reforço dos valores da empresa, que conta com personagens e especialistas para referendar a sua posição acerca da moderna socialização escolar e seu potencial de transformação.

\section{Tendências: professor capacitado}

No que diz respeito às tendências, estão em jogo para a Microsoft novos formatos de educação, modelos de gestão e a inovação na aprendizagem, que proporcionariam uma renovação para a escola, os professores e os alunos. Para a empresa, a escola seria modernizada, inovada e renovada pelas tecnologias e pelos ensinamentos que mestres e educandos passam a acessar por conta dos aparatos por ela oferecidos.

Essa escola renovada pelas tecnologias é retratada pela empresa como um espaço mais interessante, mais moderno e até mais divertido para os alunos; e apresentada como ponto de partida para a revolução que as tecnologias podem promover por meio da inclusão digital na educação. Essa inclusão é vista como fator-chave para o progresso de um Brasil que seria o motor da economia na América Latina.

Desse ponto de vista, se, por um lado, os alunos são protagonistas do impacto do trabalho da Microsoft, por outro, os professores são os personagens principais das tendências vislumbradas pela empresa. A capacitação de educadores e técnicos é afırmada e reforçada constantemente enquanto estratégia de construção da renovação da escola por meio de tecnologias. É possível verificar um exemplo no relatório de 2005, em que a Microsoft informa que:

[...] a expectativa [com a implementação do Projeto Aluno Monitor] é de que a capacitação de educadores e técnicos, além da formação de jovens estudantes, auxilie na apropriação efetiva das TICs e na multiplicação do conhecimento. (MICROSOFT BRASIL, 2005. p. 20).
A empresa explicita seu desejo de que as ferramentas - e sua lógica - sejam incorporadas pelos participantes de suas ações de formação. No relatório de 2010, a empresa explicita que "foram 36.493 educadores e 30.490 estudantes capacitados” (MICROSOFT BRASIL, 2010. p. 14). Os números estão presentes para comprovar a eficácia e a abrangência da ação; as parcerias com secretarias são mencionadas como forma de legitimação político-pedagógica da iniciativa; e, por fim, a noção de replicação deixa clara a intenção da empresa: a disseminação de seus recursos e lógicas operacionais, por meio da inclusão digital de alunos e professores.

Essa inclusão se daria quando o aluno e professor atingissem o que a empresa nomeia de potencial pleno. Para isso acontecer, os professores devem vencer uma suposta barreira que existe entre eles e seus alunos. A solução para superar esta lacuna estaria na inversão de papéis: nos projetos da empresa e nas escolas que deles participam, o aluno vira professor. Essa inversão está retratada no depoimento do aluno Helon da Rocha Gouveia Junior, que, no relatório de 2005, afirma que "a perspectiva de o aluno apoiar o professor no laboratório era pouco nítida [...] e com o programa, a barreira é derrubada" (MICROSOFT BRASIL, 2005, p. 25). A professora Kátia Cristina Botelho referenda a posição do estudante, no relatório de 2006: "Precisei muito da ajuda deles para utilizar os programas do Microsoft Office [...] eles estão se saindo ótimos professores" (MICROSOFT BRASIL, 2006, p. 19).

0 debate a respeito do papel dos professores com a modernização da educação não é recente. A academia nas áreas da comunicação e da educação se ocupa de fazer esta reflexão desde o paradigma das velhas mídias. Mas - assim como vimos que as novas mídias desfrutam de certo prestígio, enquanto as velhas mídias são historicamente vistas com maus olhos pela escola - percebe-se uma diferença de tratamento relacionada à capacitação dos professores para lidar com as tecnologias digitais. Em relação às velhas mídias, esse professor deveria 
desempenhar uma função de tutela; já em relação às novas mídias, sua posição seria a de filtro de informações e agente motivacional do aluno. Para isso, ele deve estar bem preparado para o uso consciente do potencial das tecnologias (ALMEIDA; LOBATO; GHAZIRI, 2011) e, nesse sentido, intensificam-se as demandas por formação. Por isso, em relação às novas mídias, essa preparação recebe mais ênfase, dado que a visão parece ser de que essas seriam mais complexas do que as velhas mídias; e que os jovens alunos dominam a linguagem com mais facilidade e familiaridade do que os professores. Em alguns momentos, a transformação do sistema educacional parece passar necessariamente pela transformação do professor para a resolução de um impasse instalado na educação (PRETTO, 1997).

De um modo ou de outro, o papel desse professor não é o de exercitar a crítica às tecnologias, mas, sim, de promover uma integração harmônica (OROZCO GÓMEZ, 1997) e criativa (OROZCO GÓMEZ, 2007) destas com a escola, servindo como elo de mediação dos possíveis conflitos entre a cultura escolar e a cultura digital. Ou seja, o papel desse professor é ciberalfabetizar. Esta ciberalfabetização, na visão da empresa, garantiria a professores e alunos um passaporte para os novos tempos. Por isso, mais do que incluir educadores e estudantes na era digital, a empresa deposita na inclusão digital a esperança de estender o que chama de poder digital - e os benefícios que tal poder traria - a todas as pessoas, para que elas mudem os rumos de suas vidas (MICROSOFT BRASIL, 2011). ${ }^{8}$

\section{Linguagem: alunos e professores dromoaptos}

Alunos e professores plenamente incluídos e exercendo seu potencial máximo, para proporcionar uma verdadeira revolução. Para

8- Diferentemente dos demais que foram publicados em versão impressa, o relatório de 2011 foi publicado apenas na internet em versão hotsite para navegação. Disponível em: <http://www.microsoft.com/latam/ responsabilidadsocial/2011/pt/educ/> a Microsoft, eles possuem mais em comum do que as salas de aula, os espaços da escola e os recursos e linguagens tecnológicas. Agora, eles desfrutam da mesma condição: o aluno é professor, e o professor é aluno. Todos estão juntos quando o assunto é a busca pelo poder digital.

A lógica que permeia os relatórios da empresa é a de que - de posse de uma linguagem específica informacional - os indivíduos passam a desfrutar de um tipo de poder, que os torna aptos a encarar os desafios de um mundo que é digital. Com sorte, eles se tornam até mais criativos e obstinados e, assim, as mudanças extrapolam o âmbito da educação e da escola. Por exemplo, no relatório de 2006, a inovação e a criatividade são ressaltadas enquanto valores da iniciativa Aluno Monitor:

As instituições que participam do programa se destacam com ações criativas e inovadoras. Em uma escola de Olinda (PE), por exemplo, esses jovens ajudaram a montar uma Biblioteca Virtual. (MICROSOFT BRASIL, 2006. p. 18).

Ao passar pelo Aluno Monitor e incorporar as linguagens prescritas pela empresa, uma educadora - ciberalfabetizada e, agora, ciberalfabetizadora - foi responsável pela implementação da biblioteca:

[...] além de se capacitar, a educadora fez questão de incorporar a tecnologia ao dia-a-dia da escola - conseguiu máquinas novas para o laboratório e criou, ao lado de professores e alunos, a Biblioteca Virtual, uma comunidade na Internet com o objetivo de abrigar trabalhos realizados por estudantes. (MICROSOFT BRASIL, 2006. p. 18).

Para a empresa, essa incorporação plena (de capacidade de manipular os recursos e também da lógica que eles abrigam, além da dimensão do poder digital) é fundamental. É esse processo o motor da disseminação a que 
a Microsoft se refere em seus documentos; e é essa condição que faz dos jovens soldados de um exército que vai formar novos alunos e professores nas habilidades e senhas específicas da empresa.

Os jovens que participam do projeto são nomeados Multiplicadores do Núcleo de Tecnologia Educacional (NTE). Um deles, Jairo Ribeiro, de 16 anos, tem sua história retratada no relatório de 2008:

Estudante do ensino médio, o adolescente participou do curso Aluno Monitor em sua escola, em Planaltina (DF) e passou a multiplicar o conhecimento como monitor de informática voluntário. (MICROSOFT BRASIL, 2008, p. 20)

A formação para a multiplicação dos valores da Microsoft é um complexo processo de socialização, que abrange: (1) recursos (computadores e softwares, por exemplo); (2) uma lógica específica de manipulação desses aparatos (navegação, organização e arquitetura de informação dos programas e projetos); (3) a dimensão do poder digital, valorizado tanto pela escola quanto pelo mercado de trabalho; e (4) a dinâmica proprietária dos equipamentos e programas.

Esse poder digital enfatizado pela empresa em seus documentos é considerado requisito para professores e alunos (1) transformarem suas vidas; (2) terem novas oportunidades; e, (3) em especial, para os alunos conquistarem postos desejados em um mercado de trabalho que cada vez mais exige habilidades tecnológicas. A esse poder, damos o nome de dromoaptidão. Trata-se: da "capacidade de sintonia com a velocidade estrutural das mudanças"; e do "domínio de determinados fatores de privilégio (...) as senhas infotécnicas de acesso à cibercultura" (TRIVINHO, 2007). Bourdieu (2008, p. 241) o chamaria de competência legítima.

0 importante a se entender aqui é que a dromoaptidão - conjunto de capitais informacionais - é central na ação da Microsoft e que a dinâmica de transmissão desse capital possui um aspecto de perversidade. Na medida em que os equipamentos e programas possuem uma obsolescência programada, independentemente das necessidades concretas dos usuários, se os equipamentos são constantemente renovados, “o 'capital cognitivo' dos usuários também deveria passar pelo mesmo processo, tendo que ser renovado ciclicamente" (CAZELOTO, 2005, p. 13). Estaríamos sempre atrasados?

\section{Algumas sínteses}

Neste artigo, foram analisados relatórios corporativos de cidadania da empresa Microsoft. A partir da leitura desses documentos, foi possível: (1) entender a ação da empresa no Brasil no campo da educação; e (2) visualizar as conexões entre os valores publicados pela Microsoft e o consenso em torno da moderna socialização escolar.

Viu-se que a ação da empresa em matéria de educação é ampla e envolve múltiplos campos e zonas de intervenção, caracterizando uma ação socializadora complexa que se deseja (ou que se apresenta como) inexorável ao adentrar as escolas e marcar a socialização escolar. Como fundamento dessa ação, estão valores caros à empresa e reiteradamente publicados em seus relatórios corporativos ,como inovação, mudança, inclusão social, responsabilidade social e cidadania. A iniciativa da empresa voltada para o campo da educação é caracterizada como ação social e está relacionada: (1) à socialização dos jovens, no que diz respeito ao impacto; (2) à formação dos professores para práticas educacionais inovadoras e ao progresso do país, no que diz respeito às tendências; e (3) a alunos e professores multiplicadores quando o assunto é linguagem.

Quando o que está em jogo é o impacto de seus projetos, a Microsoft está preocupada com a transformação na vida dos jovens estudantes. Sua tese é de que o poder digital, ao ser conferido, revoluciona as trajetórias dos alunos, 
marcando-as definitivamente. As disposições tecnológicas apresentadas aos alunos pela empresa enquanto instância socializadora passam por um processo de negociação, configurando novos indivíduos. Os dispositivos da cibercultura são acionados na tomada de decisão em relação à escola, à escolha profissional e a outros âmbitos de suas vidas.

A visão da empresa em relação a esses jovens é, por um lado, a de que são protagonistas de suas histórias. A Microsoft os transforma, inclusive, em grandes personagens de seus relatórios, sendo eles os agentes mais presentes nos documentos. Por outro lado, curiosamente são esses jovens o "exército de multiplicadores" do qual a empresa lança mão para reproduzir o ciclo de consagração de seus valores (e consequentemente de seus produtos) em ambientes educacionais ${ }^{9}$.

A formação para a multiplicação dos valores da empresa se estende ainda aos professores. A lógica que predomina nos textos é a de que, de posse de uma linguagem específica, os indivíduos desfrutam de um poder que os habilita para estar no mundo digital.

9- Vários são os agentes convidados a dar depoimentos nos relatórios. São consultores, diretores, estudantes, pesquisadores, presidentes da empresa, representantes do poder público e professores. Os estudantes parecem ser os grandes protagonistas. Talvez por se tratar de um texto que tem como objetivo relatar os efeitos do trabalho da empresa na área educacional e social, os personagens e suas histórias de vida alteradas pela chegada da tecnologia sejam a estratégia mais certeira para representar as transformações causadas pela ação da Microsoft. Os estudantes falam a respeito da revolução causada pelas tecnologias em suas vidas que, muitas vezes, extrapola 0 âmbito escolar. É o caso do estudante paulistano Douglas Portela de Souza, que afirma: "Eu faltava muito, não fazia as atividades que o professor pedia [...]. Aprendi a ser mais responsável no trabalho e acabei adotando essa postura também em sala de aula" (MICROSOFT BRASIL, 2009, p. 27). 0 suposto protagonismo oferecido pela empresa aos alunos nas páginas dos documentos contrasta com a visão sobre eles expressa no relatório de 2006: 0 grupo seria um exército de alunos monitores, composto por 201.673 jovens (MICROSOFT BRASIL, 2006, p. 24). 0 termo exército diz respeito à visão empresarial, que trata os jovens enquanto potenciais multiplicadores dos valores e dos recursos oferecidos pela Microsoft.
Mais do que incluir os indivíduos social e digitalmente, o poder digital caracteriza o complexo movimento de socialização levado a cabo pela empresa e que prepara os indivíduos para:

(1) manejar seus recursos;

(2) entender (e incorporar) seus valores e sua lógica de operação;

(3) reproduzir as práticas educativas, formando novos educadores, novos alunos e monitores.

Parece plausível cogitar a possibilidade de que a empresa se coloca como centro emissor de valores (de uma memória instalada de dispositivos de socialização), enquanto vê nos alunos (e também nos professores) potenciais entes indutores de seus valores e práticas para a escola e, assim, para o campo da educação. À Microsoft interessam indivíduos dromoaptos, pois eles configurarão o futuro.

Fica aqui um convite para se penetrar em um universo de sentidos que busca entender os processos de construção de um consenso tão forte, que se tornou uma fé, uma espécie de crença dificilmente questionável.

0 estudo foi motivado pelo que se confirmou ser um tipo de violência simbólica, sutil, doce e difusa, de algo que se tornou evidente e paira sobre todos os espaços. Tal violência (cujo expoente é imperativo da cibercultura sob a forma de apelo pela modernização via tecnologias) é exercida e incorporada quando agentes e instituições a submetem e a ela são submetidos de maneira aparentemente natural e destensionada. Esse retrato revela uma pulverização de ideias e representações, uma verdadeira socialização orquestrada de um consenso, matéria de investigação para o campo da sociologia da educação. 


\section{Referências}

ALMEIDA, Lígia Beatriz Carvalho de; LOBATO, Margareth Cavalcante de Castro; GHAZIRI, Samir Mustapha. ANPEd e Intercom: panorama da produção dos pesquisadores em educação e comunicação na última década. Resgate: Revista Interdisciplinar de Cultura, v. 19, p. 32-44, jul./dez. 2011.

BENJAMIN, Walter. Obras escolhidas: magia e técnica, arte e política. São Paulo: Brasiliense, 1996.

BERGER, Peter; LUCKMANN, Thomas. A construção social da realidade: tratado de sociologia do conhecimento. Petrópolis: Vozes, 1983

BOURDIEU, Pierre. A economia das trocas linguísticas. São Paulo: Edusp, 2008.

BOURDIEU, Pierre. A economia das trocas simbólicas. São Paulo: Perspectiva, 2009.

BOURDIEU, Pierre. Coisas ditas. Tradução Cássia R. da Silveira e Denise Morena Pegorim. São Paulo: Brasiliense, 2004b.

BOURDIEU, Pierre. 0 poder simbólico. Rio de Janeiro: Bertrand Brasil, 2010.

BOURDIEU, Pierre. Os usos sociais da ciência: por uma sociologia clínica do campo científico. São Paulo: Edunesp, 2004a.

CAZELOTO, Edilson. Glocal: elementos para uma crítica do modo mediático de reprodução do capitalismo tardio. Salvador: Faculdade Social da Bahia, 2005.

MARTíN-BARBERO, Jesús. Diversidad en convergencia. In: SEMINÁRIO INTERNACIONAL SOBRE DIVERSIDADE CULTURAL, Brasília, 27 a 29 de junho de 2007. Seminário... Brasília, DF: Ministério da Cultura do Brasil, 2007.

MATTELART, Armand; MATTELART, Michèle. História das teorias da comunicação. São Paulo: Loyola, 1999.

MICROSOFT BRASIL. Relatório de cidadania corporativa 2011/2012. Disponível em: <http://impactoerelevancia.blob.core. windows.net/impactoerelevancia/2012/02/Brochura_Relat\%C3\%B3rio_NCA\%20Completo.zip>. Acesso em: 29 dez. 2014.

MICROSOFT BRASIL. Relatório social 2004: compromisso com o Brasil. Disponível em: <http://www.microsoft.com/pt-br/about/ impacto-no-brasil/microsoft-no-brasil/competitividade-nacional/relatorio-anual.aspx.> Acesso em: 29 dez. 2014.

MICROSOFT BRASIL. Relatório social 2005. Disponível em: <http://www.microsoft.com/pt-br/about/impacto-no-brasil/microsoftno-brasil/competitividade-nacional/relatorio-anual.aspx>. Acesso em 29 dez. 2014.

MICROSOFT BRASIL. Relatório social 2006: seu potencial, nossa inspiração. Disponível em: <http://www.microsoft.com/pt-br/ about/impacto-no-brasil/microsoft-no-brasil/competitividade-nacional/relatorio-anual.aspx>. Acesso em 29 dez de 2014.

MICROSOFT BRASIL. Responsabilidade social corporativa. 2008. Disponível em: <http://impactoerelevancia.blob.core. windows.net/impactoerelevancia/2012/02/2008_RS2008_Microsoft_Completo.pdf>. Acesso em: 29 dez. 2014.

MICROSOFT BRASIL. Responsabilidade social corporativa. 2009. Disponível em: <http://download.microsoft.com/download/ E/2/E/E2EC2BBF-20E1-43E5-B68E-76653160F0D8/Microsoft_Brasil_Responsabilidade_social_corporativa_2009.pdf>. Acesso em: 29 dez. 2014.

OROZCO GÓMEZ, Guillermo. Podemos ser mais criativos ao adotar a inovação tecnológica em educação? Uma proposta em comunicação. Matrizes, São Paulo, v. 1, n. 1, p. 209-216, 2007.

OROZCO GÓMEZ, Guillermo. Professores e meios de comunicação: desafios e estereótipos. Comunicação \& Educação, São Paulo, n. 10, p. 57-68, 1997.

OROZCO GÓMEZ, Guillermo. Televisión, audiencias y educación. Buenos Aires: Norma, 2001. 
PRAZERES, Michelle. A moderna socialização escolar: um estudo sobre a construção da crença nas tecnologias digitais e seus efeitos para o campo da educação. 2013. Tese (Doutorado em Educação) - Faculdade de Educação, Universidade de São Paulo, São Paulo, 2013.

PRETTO, Nelson. Educação e inovação tecnológica: um olhar sobre as políticas públicas brasileiras. In: REUNIÃO ANUAL DA ANPED, 20., 1997, Caxambu, 21 a 25 de setembro de 1997. Anais..., Caxambu: Anped, 1997.

SETTON, Maria da Graça Jacintho. Família, escola e mídia: um campo com novas configurações. Educação e Pesquisa, São Paulo, v. 28, n. 1, p. 107-116, jan./jun. 2002.

SETTON, Maria da Graça Jacintho. A particularidade do processo de socialização contemporâneo. Tempo Social: Revista de Sociologia da USP, São Paulo, v. 17, n. 2, p. 335-350, nov. 2005.

SETTON, Maria da Graça Jacintho. A socialização como fato social total: notas introdutórias sobre a teoria do habitus. Revista Brasileira de Educação, v. 14, n. 41, p. 296-307, maio/ago. 2009.

SETTON, Maria da Graça Jacintho. Socialização e cultura: ensaios teóricos. São Paulo: Annablume, 2011.

TRIVINHO, Eugenio. A dromocracia cibercultural: lógica da vida humana na civilização mediática contemporânea. São Paulo: Paulus, 2007.

Recebido em: 28.10.2013

Aprovado em: 12.08.2014

Michelle Prazeres é jornalista, mestre em comunicação e semiótica (PUCSP) e doutora em educação pela Faculdade de Educação da USP. 